\title{
Management of critical-sized bone defects in the treatment of fracture-related infection: a systematic review and pooled analysis
}

\author{
H. Bezstarosti ${ }^{1}$ (D) W. J. Metsemakers ${ }^{2,5}$ - E. M. M. van Lieshout ${ }^{1}$ - L. W. Voskamp ${ }^{1} \cdot$ K. Kortram $^{1} \cdot$ M. A. McNally ${ }^{3}$. \\ L. C. Marais ${ }^{4} \cdot$ M. H. J. Verhofstad ${ }^{1}$
}

Received: 9 June 2020 / Accepted: 14 July 2020 / Published online: 29 August 2020

(c) The Author(s) 2020

\begin{abstract}
Purpose This systematic review determined the reported treatment strategies, their individual success rates, and other outcome parameters in the management of critical-sized bone defects in fracture-related infection (FRI) patients between 1990 and 2018.

Methods A systematic literature search on treatment and outcome of critical-sized bone defects in FRI was performed. Treatment strategies identified were, autologous cancellous grafts, autologous cancellous grafts combined with local antibiotics, the induced membrane technique, vascularized grafts, Ilizarov bone transport, and bone transport combined with local antibiotics. Outcomes were bone healing and infection eradication after primary surgical protocol and recurrence of FRI and amputations at the end of study period.

Results Fifty studies were included, describing 1530 patients, the tibia was affected in $82 \%$. Mean age was 40 years (range 6-80), with predominantly male subjects (79\%). Mean duration of infection was 17 months (range 1-624) and mean follow-up 51 months (range 6-126). After initial protocolized treatment, FRI was cured in 83\% (95\% CI 79-87) of all cases, increasing to 94\% (95\% CI 92-96) at the end of each individual study. Recurrence of infection was seen in 8\% (95\% CI 6-11) and amputation in 3\% (95\% CI 2-3). Final outcomes overlapped across treatment strategies.

Conclusion Results should be interpreted with caution due to the retrospective and observational design of most studies, the lack of clear classification systems, incomplete data reports, potential underreporting of adverse outcomes, and heterogeneity in patient series. A consensus on classification, treatment protocols, and outcome is needed to improve reliability of future studies.
\end{abstract}

Keywords Fracture-related infection · Bone transport · Induced membrane technique · Vascularized bone graft · Treatment

H. Bezstarosti

h.bezstarosti@erasmusmc.nl

1 Trauma Research Unit, Department of Surgery, Erasmus MC, University Medical Center Rotterdam, P.O. Box 2040, 3000 CA Rotterdam, The Netherlands

2 Department of Trauma Surgery, University Hospitals Leuven, Louvain, Belgium

3 Nuffield Orthopaedic Centre, Oxford University Hospitals, Oxford, UK

4 Department of Orthopaedics, School of Clinical Medicine, University of KwaZulu-Natal, Durban, South Africa

5 Department of Development and Regeneration, KU Leuven, Louvain, Belgium

\section{Introduction}

Segmental bone loss after trauma remains a challenging problem for orthopedic trauma surgeons. When a bone defect exists combined with fracture-related infection (FRI), the chances of successful bone consolidation and clearance of infection are reduced.

A 'critical-sized' defect is a bone defect which is not expected to heal in the absence of a secondary (surgical) intervention. There is no agreed definition of what constitutes a critical defect in humans. Court-Brown defined it [1] as a defect involving $50 \%$ of the cortical diameter with a minimum length of $1 \mathrm{~cm}$, and this was used in the Study to Prospectively evaluate Intramedullary Nails in Tibial fractures (SPRINT) [2]. A study by Sanders et al. [3] showed that, when using this definition, $47 \%$ of the bone defects 
healed without additional surgery, thus indicating that these are not always critical defects. When infection is present, it is much less likely that the fracture will heal $[4,5]$, so in this analysis, The SPRINT definition for a critical-sized defect in FRI was accepted.

Over the past decades, critical-sized bone defects in FRI have been treated using different protocols. Techniques used (e.g., Ilizarov, Papineau, Masquelet, or RIA) all have different indications and success rates, resulting in a wide range of clinical outcomes. The aim of this systematic review and pooled analysis was to evaluate identified treatment strategies, their individual success rates and other outcome parameters regarding critical-sized bone defects used between 1990 and 2018.

\section{Methods}

\section{Literature search strategy}

A literature search was completed with the help of a biomedical information specialist on June 25, 2018, using Medline, Embase, Web of Science, Cochrane, and Google Scholar. The search strings are provided in Appendix 1. Studies that described treatment of FRI using autologous cancellous grafts, autologous cancellous grafts combined with local antibiotics, the induced membrane technique, vascularized grafts, bone transport, and bone transport combined with local antibiotics were included. Series needed to be greater than five patients, reported in English, and bone defects described as $\geq 1 \mathrm{~cm}$. Studies that did not describe FRI patient treatment and publications reporting non-original data (e.g., reviews or meta-analyses), or those published before 1990, were excluded. Inclusion was agreed by two independent reviewers, HB an LWV, and consisted of two phases. During the first phase, title and abstract were screened for relevance and full text articles were obtained. When possible, full texts that were not available, were obtained by contacting the corresponding author once by email. The second phase consisted of reviewing the full text articles. Consensus was reached on all references. This study was performed using the Preferred Reporting Items for Systematic Reviews and Meta-Analyses (PRISMA) criteria [6].

\section{Data extraction}

Data from each included study were extracted by two authors independently (HB an LWV). Disagreements were discussed until agreement was reached. Data were collected in three areas.

1. General information of all studies (i.e., sample size, age, FRI, and location of FRI).
2. Data from surgical protocols (i.e., number of stages in surgical protocol, bone defect size, type of bone graft and type of fixation used).

3. Clinical outcomes (bony consolidation without infection after the primary surgical protocol, bony consolidation without infection after the study period, recurrence of FRI, amputation of the affected limb, number of complications, revision surgery, time to bony union, and Length of Hospital Stay (LOHS).

\section{Analysis}

A quality assessment of all included studies was done according to the revised and validated versions of MINORS [7]. Results for the total population were pooled and presented separately for each of the six different treatment strategies. Medcalc (MedCalc Statistical Software version 17.9.7, MedCalc Software bvba, Ostend, Belgium; http:// www.medcalc.org; 2017) was used for pooling binominal data. Heterogeneity was quantified using the Cochran's $Q$ test and $I^{2}$ statistic. When $I^{2}$ was $<40 \%$, a fixed effects model was used, and a random effects model, when $I^{2}$ was $\geq 40 \%$. Pooled estimates are reported with their $95 \%$ confidence intervals (CI). Publication bias was assessed from funnel plots for each clinical outcome and per treatment type separately. The majority of studies only provided a mean but not the standard deviation. Thus, a full meta-analysis for continuous data was not feasible. Continuous data were pooled by calculating the weighted mean using Microsoft Excel. Sample size of the individual studies was used as weighting factor. The pooled mean is reported with the range.

\section{Results}

\section{General population demographics}

After selection, 43 studies [8-50] were included describing 50 patient series in the treatment of FRI with bone defects of $\geq 1 \mathrm{~cm}$ (Fig. 1). In these studies, 1530 patients with FRI were treated, with a mean bone defect of $6.6 \mathrm{~cm}$ (range 1.0-26.0), of which 1253 (82\%) were localized at the tibia. The population had a mean age of 40 years (range 6-80), with 1176 (79\%) male patients and a mean duration of infection of 17 months (range 1-624). Mean follow-up was 51 months (range 6-126). Study characteristics and quality assessment according to the MINORS score are given in appendix 2 . The type of bone grafts used are depicted in Table 1.

Nine series (18\%) described treatment of bone defects by cancellous grafts alone and nine series (18\%) by the use of a cancellous graft in combination with local antibiotics, either beads or an antibiotic rod. The induced membrane technique was described in eight (16\%) series, and treatment with a 


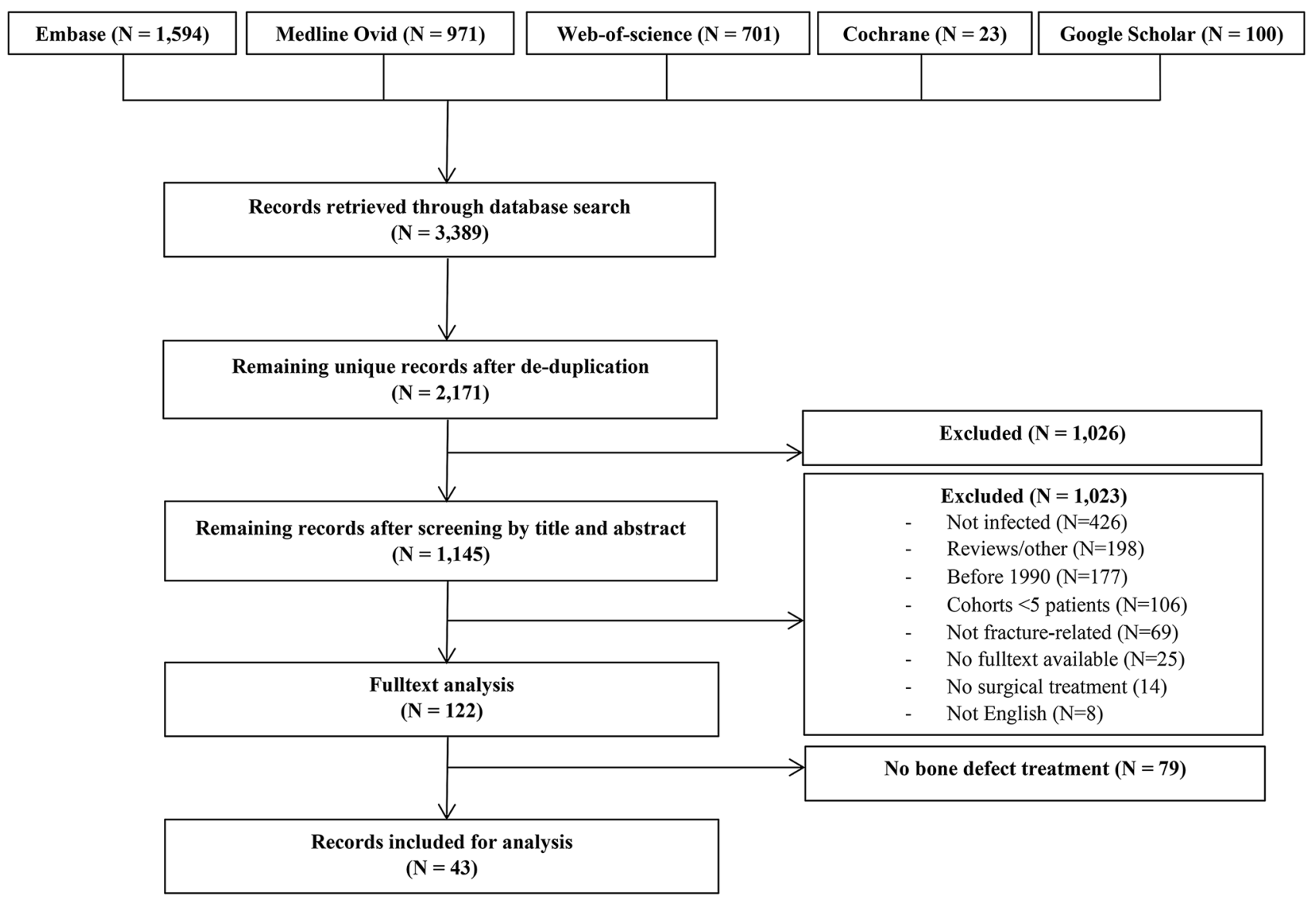

Fig. 1 Inclusion flowchart

Table 1 Bone grafts used in treatment of bone defects

\begin{tabular}{ll}
\hline Type used in total (50 patient series) & $N=1063$ (\% of total) \\
\hline Non-vascularized cancellous bone & $639(60 \%)$ \\
Iliac crest & $600(56 \%)$ \\
With granulocytes & 139 \\
With BMP-7 & 10 \\
RIA & $39(4 \%)$ \\
With BMP-7 & 37 \\
Vascularized bone & $324(30 \%)$ \\
Fibula & $260(25 \%)$ \\
Latissimus Dorsi with rib & $41(4 \%)$ \\
Ilium & $18(2 \%)$ \\
Scapula & $5(1 \%)$ \\
Other & $15(1 \%)$ \\
Mesenchymal stem cells & $70(6 \%)$ \\
Graft not defined &
\end{tabular}

$B M P$ bone morphogenetic protein, $N$ total number of bone grafts used, RIA reamer irrigator aspirator vascularized bone graft was used in four series $(8 \%)$. Bone transport alone was used in 15 series (30\%), and bone transport in combination with local antibiotic beads in $5(10 \%)$.

\section{Description by treatment type}

Table 2 summarizes the population of all treatment types and Table 3 explains all different surgical stages.

\section{Cancellous grafts (with or without local antibiotics)}

In 18 studies [9-11, 15, 17, 18, 22, 24, 26, 32-36, 38, 42, $44,49](36 \%)$, a total of $472(31 \%)$ patients were treated with a cancellous bone graft, half of these studies used a cancellous graft only, the other half used a cancellous bone graft after local antibiotics treatment with either Polymethyl methacrylate (PMMA) beads or a cement rod.

The 9 studies (18\%) describing treatment with a cancellous graft only included $311(20 \%)$ patients, with a mean age of 40 years (range 16-68) and a mean bone defect of $4.6 \mathrm{~cm}$ (range 1-16). Four studies (44\%), used a one-stage reconstruction, three studies (33\%) a two-stage, and one study 
Table 2 Study characteristics

\begin{tabular}{llllll}
\hline Overall & $\begin{array}{l}\text { Series }(N) \\
50\end{array}$ & $\begin{array}{l}\text { Patients }(N) \\
1530\end{array}$ & $\begin{array}{l}\text { Age (years) } \\
40(6-80)\end{array}$ & $\begin{array}{l}\text { FU (months) } \\
51(6-126)\end{array}$ & $\begin{array}{l}\text { Defect size }(\mathrm{cm}) \\
6.6(1-26)\end{array}$ \\
\hline $\begin{array}{l}\text { Surgical protocol } \\
\text { Cancellous graft only }\end{array}$ & 9 & 311 & $40(16-68)$ & $61(10-120)$ & $4.6(1-16)$ \\
Cancellous graft with AB & 9 & 161 & $37(18-79)$ & $43(24-126)$ & $4.9(1-12)$ \\
Induced membrane & 8 & 177 & $42(16-72)$ & $26(13-72)$ & $4.5(1-26)$ \\
Vascularized graft & 4 & 322 & $43(6-69)$ & $75(6-86)$ & $10.7(1-21)$ \\
Bone transport only & 15 & 395 & $37(17-80)$ & $34(12-106)$ & $5.5(1-21)$ \\
Bone transport with AB & 5 & 164 & $43(15-68)$ & $49(12-102)$ & $5.7(3-14)$ \\
\hline
\end{tabular}

Age; $F U$ follow-up; and defect size are depicted by mean (range); $A B$ antibiotics

Table 3 Surgical stages explained

\begin{tabular}{ll}
\hline Surgical protocol (series) & Stage description [References] \\
\hline $\begin{array}{l}\text { Cancellous graft only [9] } \\
\text { One stage [4] }\end{array}$ & $\begin{array}{l}\text { Debr. CBG [15, 18, 22, 42] } \\
\text { Two stage [3] }\end{array}$ \\
$\begin{array}{l}\text { Debr. delayed CBG [26, 36, 44] } \\
\text { Three stage [1] }\end{array}$ & Debr. delayed CBG, delayed STC [33] \\
Cancellous graft with AB [9] & \\
Two stage [6] & Debr. local AB, delayed CBG and def. fix [10, 24, 32, 34, 35, 38] \\
Three stage [2] & Debr. two times local AB, delayed CBG and def. fix [11] \\
& Debr. local AB, delayed STC, delayed CBG and def. fix [49] \\
Induced membrane [8] & Debr. local AB, delayed CBG and def. fix. [23, 29, 30, 34, 37, 40, 43, 48] \\
Two stage [8] & \\
Vascularized graft [4] & Debr. VBG [16, 46] \\
One stage [2] & Debr. local AB, VBG [41] \\
Two stage [1] & \\
Bone transport only [15] & Debr. Ilizarov application [8, 14, 25-28, 36, 38, 39, 47, 50] \\
One stage [12] & Debr. delayed tibia osteotomy, arthrodesis ankle [12] \\
Three stage [1] & \\
Bone transport with AB [5] & Debr. CaSO4 AB pellets, Ilizarov application [40] \\
One stage [1] & Debr. local AB, delayed Ilizarov application [13, 18, 20, 31] \\
Two stage [4] & [9, 17, 19, 21, 45] \\
Unspecified [5] & \\
\hline
\end{tabular}

$A B$ antibiotics, Debr debridement, $C B G$ cancellous bone graft, $S T C$ soft tissue coverage, $A B$ antibiotics, def. fix. definitive fixation, $V B G$ vascularized bone graft
(11\%) a three-stage. One study (11\%) did not describe the number of stages.

The other 9 studies (18\%), which used a cancellous graft after placement of PMMA beads or a cement rod, described the treatment of $161(11 \%)$ patients. The mean patient age was 37 years (range 18-79) and the mean bone defect length was $4.9 \mathrm{~cm}$ (range 1-12). The majority, 67\%, were treated by a two-stage protocol, two studies $(22 \%)$ used a threestage protocol and one (11\%) did not mention the number of stages. Mean time between placement and removal of the antibiotic carrier was 31 days.

\section{Induced membrane technique}

Eight series [23, 29, 30, 34, 37, 40, 43, 48] (16\%) described the treatment of $177(12 \%)$ patients, with a mean age of 42 years (range 16-72), a mean bone defect size of $4.5 \mathrm{~cm}$ (range 1.0-26.0), that were followed-up for a mean of 26 months (range 13-72). All eight studies used a two-stage reconstruction protocol with an antibiotic loaded cement spacer, which was removed after a mean time of 68 days. 


\section{Vascularized grafts}

In four $(8 \%)$ studies $[16,21,41,46]$, a total of $322(21 \%)$ patients were treated with a vascularized bone graft all using mixed, internal and external, fixation protocols. Two studies (50\%) used a single-stage procedure, one study (25\%) a two-stage procedure, and one study (25\%) did not describe the number of stages. Their mean patient age was 43 years (range 6-69), with a mean defect size of $10.7 \mathrm{~cm}$ (range 1.0-21.0), and a mean follow-up of 75 months (range 6-86).

\section{Bone transport}

In 20 studies [8, 12-14, 18-20, 25-28, 31, 36, 38-40, 45, $47,50](40 \%), 559(37 \%)$ patients were treated using a bone transport technique. In 15 (75\%) of these studies, bone transport was used without the use of local antibiotic therapy. These series described the treatment of 395 (26\%) patients with FRI, with a mean age of 37 years (range 17-80), and a mean defect length of $5.5 \mathrm{~cm}$ (range 1-21). Twelve studies $(80 \%)$ mentioned a one-stage bone transport procedure, one (2\%) described a three-stage bone transport procedure with open wound treatment, and two (4\%) did not mention the number of stages.

The remaining five studies (26\%) used a combination of bone transport and local antibiotics to treat $164(11 \%)$ patients, aged 43 years (range 15-68), with a mean bone defect of $5.7 \mathrm{~cm}$ (range 3-14). All studies used local antibiotics in the form of beads, four studies (80\%) used PMMA as a carrier in a two-stage design, and one (20\%) used calcium sulphate pellets in a one-stage protocol. Mean time before removal of the PMMA beads was 42 days.

\section{Clinical outcome of all studies}

After initial protocolized treatment, FRI was cured and bone defects healed in $83 \%$ (95\% CI 79-87) of all cases, increasing to $94 \%$ (95\% CI 92-96) with further treatment, at the end of the total study period. Recurrence of infection was seen in $8 \%$ (95\% CI 6-11), and amputation in 3\% (95\% CI $2-3)$ of all cases.

Figure 2 shows the clinical outcome for all studies. Final outcomes overlapped across all different treatments. The use of the induced membrane or bone transport technique shows a trend of increased recurrence of infection when compared to the other techniques. Reconstruction with the induced membrane technique, a vascularized graft, or bone transport with local antibiotics tends to lead to a larger amputation rate than the bone transport and two other cancellous graft treatments alone. Funnel plots assessing publication bias for each clinical outcome are presented per treatment type in Appendix 3. The funnel plots of primary and total healing both show comparable asymmetry, possibly due the smaller studies having worse outcome. Publication bias could have occurred because of different study size populations in mostly retrospective series underreporting negative outcomes. This could also be the case for the funnel plots depicting recurrence of infection and amputation ratio. Half of all studies do not report recurrence of infection, possibly due to better surgical protocols, or underreporting of negative clinical outcome in mostly retrospective series. Forest plots depicting clinical outcome per treatment type are given in Appendix 4.

Figure 3 shows the weighted means for all continuous outcomes. In 33 (66\%) studies reporting time to union, bony union was achieved after a mean of 6.7 months. Patients were hospitalized for a mean of 1.7 months. A mean of 0.7 complications per patients were recorded, i.e. superficial or deep infection, hemorrhage, deformities, and non-union. Almost one-third of all patients required at least one reoperation. Overall time to union, LOHS, complication rate per patient, and surgical revisions per patient could not be compared between groups. The use of vascularized grafts tends to have a shorter time of union, number of complications and less necessary surgical revisions when compared to the other groups.

\section{Discussion}

Adequate debridement of non-viable bone remains one of the cornerstones of the management of FRI [51, 52]. This debridement, along with the bone loss that occurs at the time of the initial trauma and due to the infectious process itself, frequently results in the presence of significant bone defects in patients with FRI. The optimal management of these bone defects remains controversial, leading to the numerous techniques described [53].

This systematic review revealed that the current most popular techniques resulted in comparable rates of healing and recurrence of infection. It is however unlikely that one reconstruction technique will be able to address all types of bone defects in FRI patients. Kadhim et al. [54] reviewed the use of bone transport or a vascularized bone graft for reconstruction of segmental bone defects, showing different success rates at different anatomical locations. Other recent reports have raised concern with regards to the efficacy of the induced membrane technique, for example, as a reconstruction technique of post-infective tibial shaft defects $[30,55,56]$. The need therefore is to determine what technique would be deemed optimal in a certain specific clinical scenario.

Due to several factors, it was not possible to draw firm conclusions from the data in this regard. Firstly, the heterogeneity of the patient populations made comparison of outcomes difficult. There was, for example, a difference in 


\section{Primary healing}

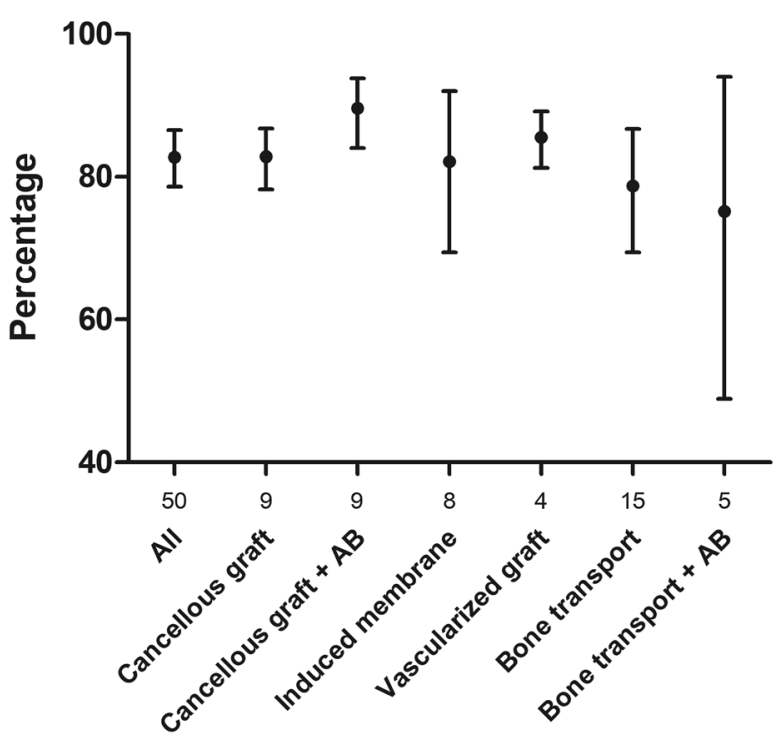

Recurrence

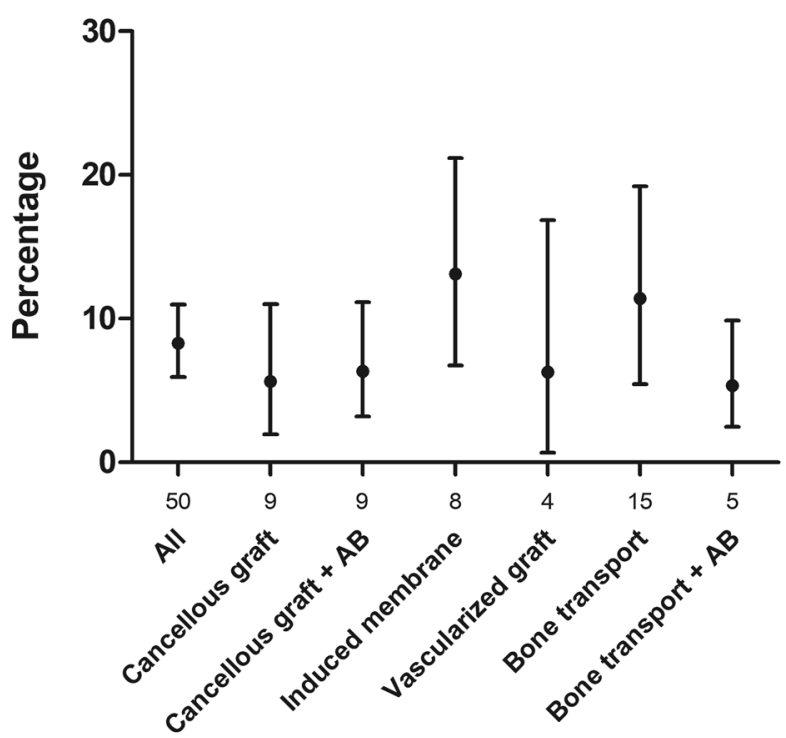

Total healing

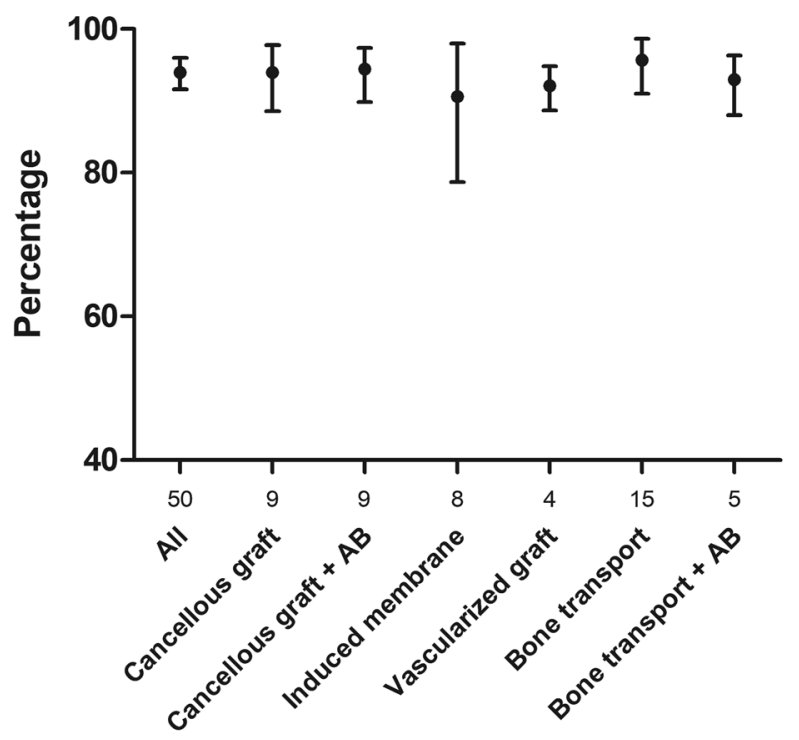

Amputation

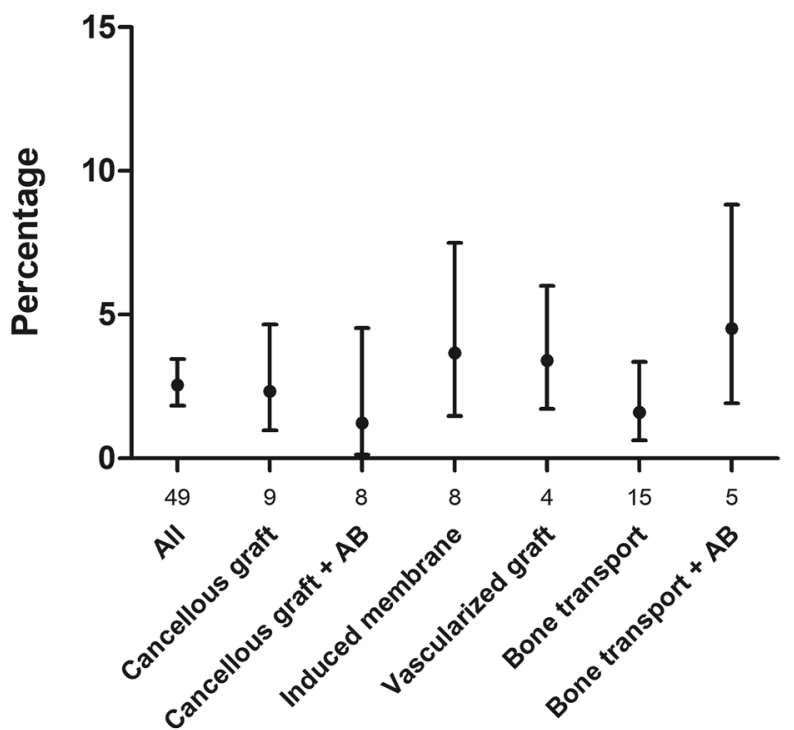

Fig. 2 Proportional clinical outcome. Numbers under the $X$-axis represent the number of studies for which data are pooled; $A B$ local antibiotics

the mean size of the defects among the different treatment groups. Series describing the use of vascularized grafts or bone transport techniques treated larger bone defects than series using cancellous grafts. Also, in studies describing a two-stage reconstruction protocol, often more surgical revisions were performed than initially expected.

The choice of reconstruction technique depends on many factors. These include the host's physiological status and ability to participate in the rehabilitation program, the shape and location of the defect, duration of the defect (i.e., acute/ early or chronic/late-onset), quality of the surrounding soft tissue, bone quality, the presence of deformity, adjacent joint contracture/instability or limb length discrepancy, as well as the experience of the surgeon [57]. Unfortunately, the published series do not always report the details of these factors. It is often impossible to understand how patients 
Time to union

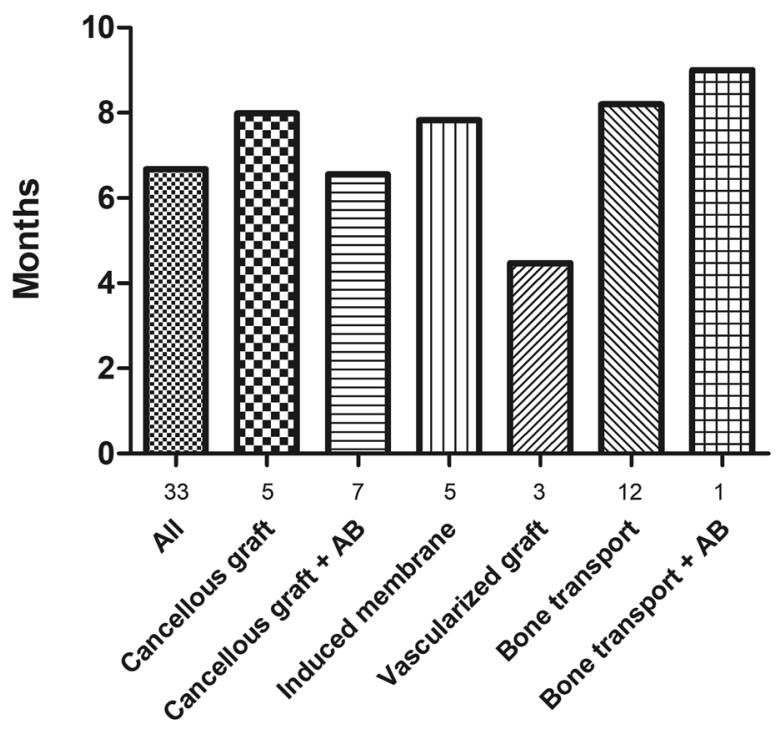

Complications

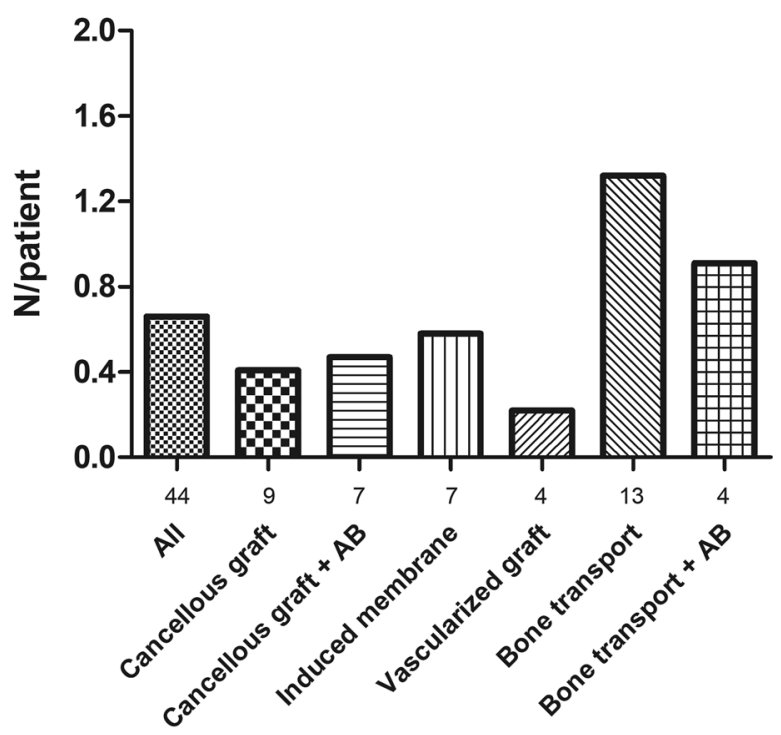

LOHS

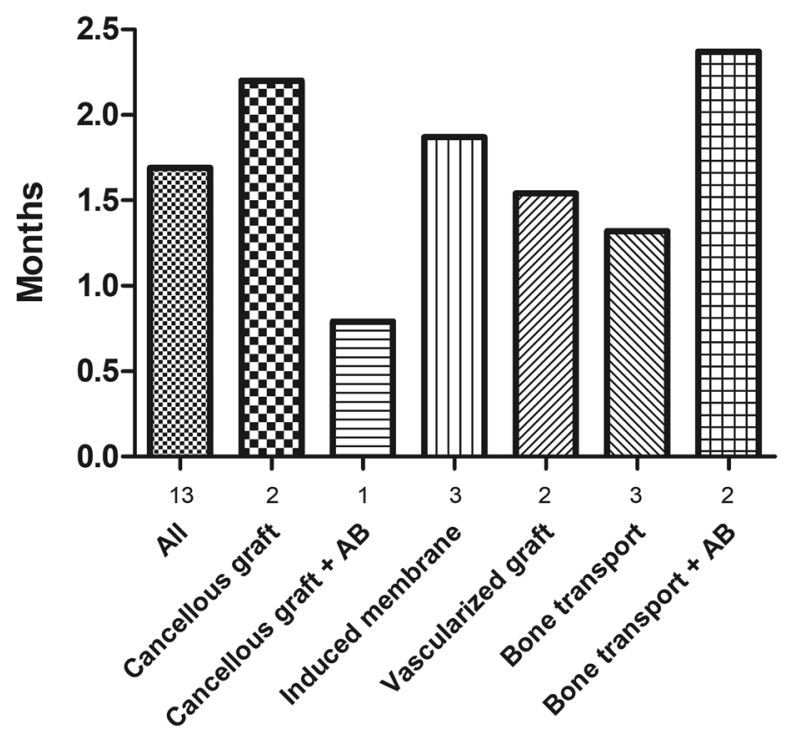

Surgical revisions

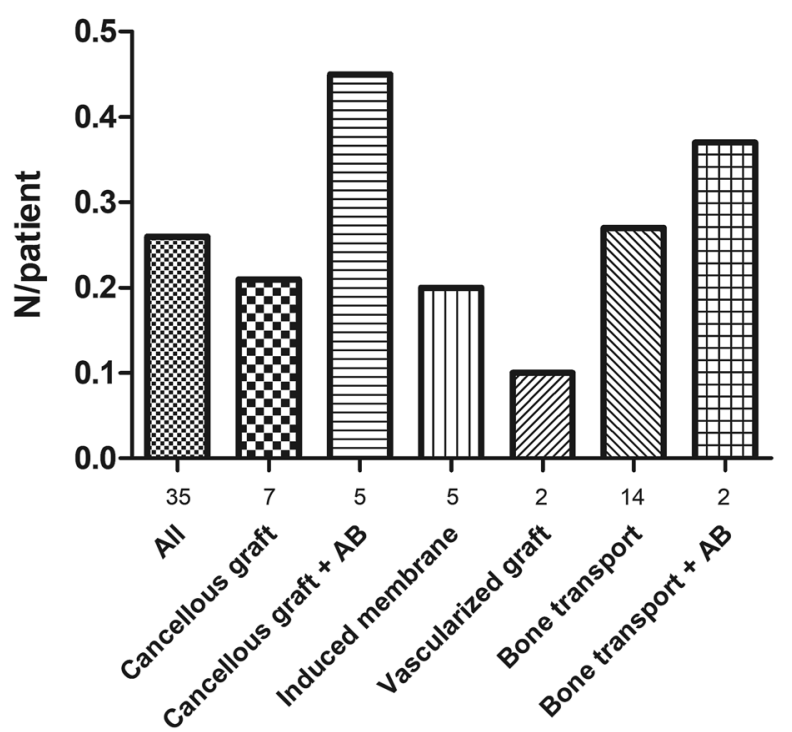

Fig. 3 Clinical outcome by weighted mean. Numbers under the $X$-axis represent the number of studies for which data are pooled; $A B$ local antibiotics

were selected for a particular technique. This deficit makes comparison of outcomes difficult. The outcome of the use of one technique in compromised hosts with tibial defects, for example, cannot be compared with the results of another technique in optimized hosts in the upper limb.

Most studies provide a cohort of cases treated with a single technique, rather than a consecutive series of patients, selected because of the characteristics of the disease [58].
This makes firm conclusions on the efficacy of a technique in a patient population impossible [59].

Secondly, of all included series, 12 (24\%) [20, 23, 32, 33, $35,37,40,41,43,46,47]$ describe FRI on multiple anatomical locations, and six (12\%) [8, 12, 17, 38, 48] describe FRI of the femur, ankle or foot. Although these series are low in number of patients, data pooling still results in a distorted outcome. 
The current lack of a universally accepted classification system for both FRI and post-infective bone defects is evident in this systematic review. The need remains for the development of a pragmatic classification system that can be used, not only to guide treatment, but also to adequately characterize the patient cohort for research purposes [60-62]. Similarly, traditional classification systems for post-infective bone defects have failed to keep up with contemporary trends in reconstruction. The classification of post-infective tibial bone defects proposed by May and Jupiter, for example, does not cater for the induced membrane technique [63].

In addition to the lack of an applicable classification of post-infective bone defects, a working definition of defects is needed which cannot be expected to heal without intervention. While the difference between a stable cavitory (contained) defect and an unstable defect may be apparent, there may be a need to further define critical unstable defects to investigate the outcomes of treatment modalities in different types of critical bone defects. This definition, together with a pragmatic classification would allow the development of a practical algorithm for management of these infected defects. It may be foreseen that a $4 \mathrm{~cm}$ conical (partial) humeral defect with $20 \%$ cortical bone contact may be treated differently than a $4 \mathrm{~cm}$ segmental (complete) tibial defect, for example [64].

In addition to the lack of uniformity in terms of patient population, numerous other factors prohibit direct comparison of results from the studies included in this systematic review. Due to the retrospective and observational nature of most studies, treatment strategy selection was not always clearly reported and may not have been consistent. Furthermore, data were not always sufficiently complete to allow comparison of outcomes. For continuous outcomes, most studies failed to report the standard deviation along with the mean value. Underreporting of adverse effects is of particular concern, especially if risks associated with a specific treatment option in a specific clinical setting should be taken into account when choosing a reconstructive option. When looking at the asymmetrical form of the funnel plots created for all clinical outcomes, this could be the case, as is discussed above.

Mauffrey and Hak [55] have recently highlighted the lack of standardization in the management algorithms for tibial defect reconstruction, particularly in the setting of postinfective defects where treatment strategy selection is often based on surgeon preference rather than scientific evidence [65]. Similarly, Makridis et al. [65] found great heterogeneity of studies in the field of FRI, which made the development of evidenced-based management protocols difficult. The lack of comparative studies is also evident. While bone transport and the induced membrane technique remain two popular treatment options, there is no high-quality evidence indicating that one is superior to the other [66], or which patients are best suited to each technique. This systematic review confirmed that evidence to make any high-level recommendation with regard to the management of post-infective bone defects in FRI patients is currently insufficient.

It is unlikely that one single, high volume center is able to adequately study the problem of FRI. Even in such referral centers the number of patients treated in a reasonable time span is not sufficient to achieve enough statistical power to draw firm conclusions on current treatment standards and new therapeutic options. This implies that (international) collaboration is essential to be able to pool treatment results from individual hospitals into (prospective) clinical studies and subsequently into meaningful meta-analyses. Only then, can adequate progress in the treatment of FRI be made. To facilitate such a collaboration, uniform definitions for classification, diagnostic and treatment protocols and follow-up are required. The current meta-analysis clearly shows that the way in which data have been collected and reported in the past cannot inform best practice in the future.

\section{Conclusions}

This is the first extensive review of bone defect treatment protocols for FRI. Six individual treatment protocols for FRI treatment were identified, i.e., cancellous grafts with or without the use of local antibiotics, the induced membrane technique, the use of vascularized grafts, or the Ilizarov bone transport technique with or without the use of local antibiotics. All show comparable outcome. Overall published work showed a high success rate of $94 \%$, a recurrence rate of $8 \%$, and low amputation rate of only $3 \%$. However, data did not allow a reliable comparison across treatments, or a recommendation on which treatment strategy is appropriate for any particular clinical scenario. The results should thus be interpreted with caution due to the retrospective design of most studies, the lack of clear classification systems, incomplete data reports, underreporting of adverse outcomes, and heterogeneity in patient series. Secondly, this review reveals the true scientific and clinical needs: uniform definitions on terms used, a consensus on classification, structured treatment protocols, and clear outcome parameters are needed to improve reliability of future multicenter studies.

Acknowledgements The authors thank Mr. Wichor M. Bramer, biomedical information specialist (Erasmus MC, University Medical Center Rotterdam, Rotterdam, The Netherlands), for his help in conducting the systematic literature search.

Author contributions HB, WJM, EMMVL, KK, and MHJV designed the study. HB, LWV, and KK collected data, HB and LWV constructed the database. HB and EMMVL performed the statistical analysis. HB and WJM drafted the manuscript. All authors interpreted the data, 
critically revised the manuscript, and approved the final version. EMMVL attests that all listed authors meet authorship criteria and that no others meeting the criteria have been omitted. EMMVL is the guarantor of the paper and takes responsibility for the integrity of the work from inception to published article.

Funding There is no funding source.

\section{Compliance with ethical standards}

Conflict of interest The authors declare that they have no conflict of interest.

Ethical approval This article does not contain any studies with human participants or animals performed by any of the authors.

Open Access This article is licensed under a Creative Commons Attribution 4.0 International License, which permits use, sharing, adaptation, distribution and reproduction in any medium or format, as long as you give appropriate credit to the original author(s) and the source, provide a link to the Creative Commons licence, and indicate if changes were made. The images or other third party material in this article are included in the article's Creative Commons licence, unless indicated otherwise in a credit line to the material. If material is not included in the article's Creative Commons licence and your intended use is not permitted by statutory regulation or exceeds the permitted use, you will need to obtain permission directly from the copyright holder. To view a copy of this licence, visit http://creativecommons.org/licenses/by/4.0/.

\section{Appendix 1: Search terms used for the individual databases}

(A) Medline OVID: ("osteitis"/ OR "osteomyelitis"/ OR (osteitis OR osteomyelitis).ab,ti.) AND (exp "Fractures, Bone"/ OR (fracture* OR nonunion* OR malunion* OR nonunited* OR malunited* OR posttraum* OR posttraum*).ab,ti.) AND ("Surgical Procedures, Operative"/ OR "debridement"/ OR osteitis/su OR osteomyelitis/su OR (surger* OR surgic* OR debridement*).ab,ti.) AND ("observational study"/ OR exp "Cohort Studies"/ OR "Case-Control Studies"/ OR "Cross-Sectional Studies"/ OR "multicenter study"/ OR "comparative study"/ OR "clinical study"/ OR exp "clinical trial"/ OR "Random Allocation"/ OR exp "treatment outcome"/ OR (((observation* OR comparativ*) ADJ6 (stud* OR data OR research)) OR cohort* OR longitudinal* OR retrospectiv* OR prospectiv* OR ((case OR cases OR match*) ADJ3 control*) OR (cross ADJ section*) OR correlation* OR multicenter* OR multicenter* OR follow-up* OR followup* OR clinical* OR trial OR random* OR (treatment ADJ3 (outcome* OR fail* OR success*))).ab,ti.) NOT (letter OR news OR comment OR editorial OR congresses OR abstracts).pt. AND english.la.
(B) Embase: ('osteitis'/de OR 'osteomyelitis'/ de OR 'chronic osteomyelitis'/de OR (osteitis OR osteomyelitis):ab,ti) AND ('fracture'/exp OR 'posttraumatic complication'/de OR (fracture* OR nonunion* OR malunion* OR nonunited* OR malunited* OR posttraum* OR post-traum*):ab,ti) AND ('surgery'/de OR 'surgical technique'/de OR 'debridement'/de OR 'osteitis'/exp/ dm_su OR (surger* OR surgic* OR debridement*):ab,ti) AND ('observational study'/exp OR 'cohort analysis'/ exp OR 'longitudinal study'/exp OR 'retrospective study'/ exp OR 'prospective study'/exp OR 'case control study'/ de OR 'cross-sectional study'/de OR 'correlational study'/ de OR 'major clinical study'/de OR 'multicenter study'/de OR 'comparative study'/de OR 'follow up'/de OR 'clinical study'/de OR 'clinical article'/de OR 'clinical trial'/exp OR 'randomization'/exp OR 'intervention study'/de OR 'open study'/de OR 'treatment outcome'/exp OR (((observation* OR comparativ*) NEAR/6 (stud* OR data OR research)) OR cohort* OR longitudinal* OR retrospectiv* OR prospectiv* OR ((case OR cases OR match*) NEAR/3 control*) OR (cross NEXT/1 section*) OR correlation* OR multicenter* OR multi-center* OR follow-up* OR followup* OR clinical* OR trial OR random* OR (treatment NEAR/3 (outcome* OR fail* OR success*))):ab,ti) NOT ([Conference Abstract]/lim OR [Letter]/lim OR [Note]/lim OR [Editorial]/ lim) AND [english]/lim.

(C) Web of Science: TS $=((($ osteitis OR osteomyelitis $))$ AND ((fracture* OR nonunion* OR malunion* OR nonunited* OR malunited* OR posttraum* OR post-traum*)) AND ((surger* OR surgic* OR debridement*)) AND ((((observation* OR comparativ*) NEAR/5 (stud* OR data OR research)) OR cohort* OR longitudinal* OR retrospectiv* OR prospectiv* OR ((case OR cases OR match*) NEAR/2 control*) OR (cross NEAR/1 section*) OR correlation* OR multicenter* OR multi-center* OR follow-up* OR followup* OR clinical* OR trial OR random* OR (treatment NEAR/2 (outcome* OR fail* OR success*))))) AND $\mathrm{DT}=($ article $)$ AND LA $=($ english $)$.

(D) Cochrane: ((osteitis OR osteomyelitis):ab,ti) AND ((fracture* OR nonunion* OR malunion* OR nonunited* OR malunited* OR posttraum* OR post-traum*):ab,ti) AND ((surger* OR surgic* OR debridement*):ab,ti).

(E) Google scholar: "posttraumaticltraumatic osteitislosteomyelitis" surgerylsurgicalldebridement all intitle:"posttraumaticltraumatic osteitislosteomyelitis" surgerylsurgicalldebridement 


\section{Appendix 2: Study characteristics and quality control}

\begin{tabular}{|c|c|c|c|c|c|c|c|c|}
\hline References & $\operatorname{Pt}(N)$ & $\begin{array}{l}\text { Pct. males } \\
(\%)\end{array}$ & $\begin{array}{l}\text { FRI loca- } \\
\text { tion }\end{array}$ & $\begin{array}{l}\text { Pct. tibia } \\
(\%)\end{array}$ & $\begin{array}{l}\text { Surgical } \\
\text { protocol }\end{array}$ & Type & LoE & $\begin{array}{l}\text { MINORS } \\
\text { score }\end{array}$ \\
\hline Campbell et al. [9] & 12 & 67 & $\mathrm{~T}$ & 100 & CG & $\begin{array}{l}\text { Retrospective } \\
\text { cohort }\end{array}$ & 4 & $5^{\mathrm{b}}$ \\
\hline Deng et al. [15] & 15 & 60 & $\mathrm{~T}$ & 100 & CG & $\begin{array}{l}\text { Retrospective } \\
\text { cohort }\end{array}$ & 4 & $4^{b}$ \\
\hline Eralp et al. [17] & 45 & 84 & $\mathrm{~T}$ & 100 & $\mathrm{CG}$ & $\begin{array}{r}\text { Retrospective } \\
\text { comparison }\end{array}$ & 3 & $11^{\mathrm{c}}$ \\
\hline Hernigou et al. [22] & 80 & 70 & $\mathrm{~T}$ & 100 & CG & $\begin{array}{l}\text { Prospective com- } \\
\text { parison }\end{array}$ & 2 & $14^{\mathrm{c}}$ \\
\hline Marsh et al. [26] & 15 & 87 & $\mathrm{~T}$ & 100 & CG & $\begin{array}{r}\text { Retrospective } \\
\text { comparison }\end{array}$ & 3 & $9^{c}$ \\
\hline Polyzois et al. [33] & 31 & 100 & $\mathrm{~T}, \mathrm{f}$ & 68 & CG & $\begin{array}{l}\text { Retrospective } \\
\text { cohort }\end{array}$ & 4 & $5^{\mathrm{b}}$ \\
\hline Sadek et al. [36] & 16 & 75 & $\mathrm{~T}$ & 100 & CG & $\begin{array}{c}\text { Retrospective } \\
\text { comparison }\end{array}$ & 3 & $12^{\mathrm{c}}$ \\
\hline Vitkus et al. [42] & 29 & - & $\mathrm{T}$ & 100 & $\mathrm{CG}$ & $\begin{array}{l}\text { Retrospective } \\
\text { cohort }\end{array}$ & 4 & $3^{\mathrm{b}}$ \\
\hline Wang et al. [44] & 68 & 71 & $\mathrm{~T}$ & 100 & CG & $\begin{array}{c}\text { Retrospective } \\
\text { comparison }\end{array}$ & 3 & $11^{\mathrm{c}}$ \\
\hline Chan et al. [10] & 36 & 83 & $\mathrm{~T}$ & 100 & CGAB & $\begin{array}{l}\text { Retrospective } \\
\text { cohort }\end{array}$ & 4 & $2^{\mathrm{b}}$ \\
\hline Chen et al. [11] & 18 & 83 & $\mathrm{~T}$ & 100 & CGAB & $\begin{array}{l}\text { Retrospective } \\
\text { cohort }\end{array}$ & 4 & $5^{\mathrm{b}}$ \\
\hline Eralp et al. [17] & 13 & 69 & $\mathrm{~A}$ & 0 & CGAB & $\begin{array}{l}\text { Retrospective } \\
\text { cohort }\end{array}$ & 4 & $11^{\mathrm{c}}$ \\
\hline Lin et al. [24] & 16 & 88 & $\mathrm{~T}$ & 100 & CGAB & $\begin{array}{l}\text { Retrospective } \\
\text { cohort }\end{array}$ & 4 & $2^{\mathrm{b}}$ \\
\hline Patzakis et al. [32] & 33 & 82 & $\mathrm{~T}, \mathrm{~F}, \mathrm{U}$ & 67 & CGAB & Prospective cohort & 4 & $8^{\mathrm{b}}$ \\
\hline Qiu et al. [34] & 18 & 83 & $\mathrm{~T}$ & 100 & CGAB & $\begin{array}{r}\text { Retrospective } \\
\text { comparison }\end{array}$ & 3 & $11^{\mathrm{c}}$ \\
\hline Reichert et al. [35] & 14 & 79 & $\mathrm{~T}, \mathrm{~F}, \mathrm{R}, \mathrm{H}$ & 29 & CGAB & $\begin{array}{l}\text { Retrospective } \\
\text { cohort }\end{array}$ & 4 & $5^{\mathrm{b}}$ \\
\hline Shyam et al. [38] & 7 & 86 & $\mathrm{~F}$ & 0 & CGAB & $\begin{array}{l}\text { Prospective com- } \\
\text { parison }\end{array}$ & 2 & $14^{\mathrm{c}}$ \\
\hline Zalavras et al. [49] & 6 & 83 & $\mathrm{~T}$ & 100 & CGAB & $\begin{array}{l}\text { Retrospective } \\
\text { cohort }\end{array}$ & 4 & $6^{\mathrm{b}}$ \\
\hline Jeong et al. [23] & 15 & 67 & $\mathrm{~T}, \mathrm{~A}, \mathrm{~F}$ & 47 & $\mathrm{IM}$ & $\begin{array}{l}\text { Retrospective } \\
\text { cohort }\end{array}$ & 4 & $5^{\mathrm{b}}$ \\
\hline Moghaddam et al. [29] & 50 & 84 & $\mathrm{~T}$ & 100 & $\mathrm{IM}$ & $\begin{array}{l}\text { Prospective com- } \\
\text { parison }\end{array}$ & 2 & $16^{\mathrm{c}}$ \\
\hline Morris et al. [30] & 12 & 75 & $\mathrm{~T}$ & 100 & IM & $\begin{array}{l}\text { Retrospective } \\
\text { cohort }\end{array}$ & 4 & $4^{\mathrm{b}}$ \\
\hline Qiu et al. [34] & 22 & 82 & $\mathrm{~T}$ & 100 & IM & $\begin{array}{r}\text { Retrospective } \\
\text { comparison }\end{array}$ & 3 & $11^{\mathrm{c}}$ \\
\hline Scholz et al. [37] & 13 & 92 & $\mathrm{~T}, \mathrm{f}, \mathrm{F}, \mathrm{R}$ & 38 & IM & $\begin{array}{l}\text { Retrospective } \\
\text { cohort }\end{array}$ & 4 & $6^{\mathrm{b}}$ \\
\hline Tong et al. [40] & 20 & 75 & $\mathrm{~T}, \mathrm{~F}$ & 65 & $\mathrm{IM}$ & $\begin{array}{r}\text { Retrospective } \\
\text { comparison }\end{array}$ & 3 & $14^{\mathrm{c}}$ \\
\hline Wang et al. [43] & 32 & 69 & $\mathrm{~T}, \mathrm{~F}$ & 63 & IM & $\begin{array}{l}\text { Retrospective } \\
\text { cohort }\end{array}$ & 4 & $7^{\mathrm{b}}$ \\
\hline Yu et al. [48] & 13 & 69 & $\mathrm{~F}$ & 0 & IM & $\begin{array}{l}\text { Retrospective } \\
\text { cohort }\end{array}$ & 4 & $8^{\mathrm{b}}$ \\
\hline Yang et al. [46] & 51 & 84 & $\mathrm{~T}, \mathrm{~F}$ & 92 & VG & Prospective cohort & 4 & $9^{b}$ \\
\hline
\end{tabular}




\begin{tabular}{|c|c|c|c|c|c|c|c|c|}
\hline References & $\operatorname{Pt}(N)$ & $\begin{array}{l}\text { Pct. males } \\
(\%)\end{array}$ & $\begin{array}{l}\text { FRI loca- } \\
\text { tion }\end{array}$ & $\begin{array}{l}\text { Pct. tibia } \\
(\%)\end{array}$ & $\begin{array}{l}\text { Surgical } \\
\text { protocol }\end{array}$ & Type & $\mathrm{LoE}$ & $\begin{array}{l}\text { MINORS } \\
\text { score }\end{array}$ \\
\hline Doi et al. [16] & 26 & 85 & $\mathrm{~T}$ & 100 & VG & $\begin{array}{l}\text { Retrospective } \\
\text { cohort }\end{array}$ & 4 & $3^{b}$ \\
\hline Erdinger et al. [21] & 5 & 80 & $\mathrm{~T}$ & 100 & VG & $\begin{array}{l}\text { Retrospective } \\
\text { cohort }\end{array}$ & 3 & $5^{\mathrm{b}}$ \\
\hline Tu and Yen [41] & 240 & 84 & $\mathrm{~T}, \mathrm{~A}, \mathrm{~F}$ & 67 & VG & $\begin{array}{l}\text { Retrospective } \\
\text { cohort }\end{array}$ & 4 & $6^{\mathrm{b}}$ \\
\hline Barbarossa et al. [8] & 30 & 80 & $\mathrm{~F}$ & 0 & BT & $\begin{array}{l}\text { Retrospective } \\
\text { cohort }\end{array}$ & 4 & $2^{\mathrm{b}}$ \\
\hline Chen et al. [12] & 12 & 100 & A & 0 & BT & $\begin{array}{l}\text { Retrospective } \\
\text { cohort }\end{array}$ & 4 & $5^{\mathrm{b}}$ \\
\hline Dendrinos et al. [14] & 28 & 82 & $\mathrm{~T}$ & 100 & BT & $\begin{array}{l}\text { Retrospective } \\
\text { cohort }\end{array}$ & 4 & $4^{\mathrm{b}}$ \\
\hline Eralp et al. [19] & 43 & 91 & $\mathrm{~T}$ & 100 & BT & $\begin{array}{r}\text { Retrospective } \\
\text { comparison }\end{array}$ & 3 & $9^{\mathrm{b}}$ \\
\hline Liu et al. [25] & 35 & 71 & $\mathrm{~T}$ & 100 & BT & $\begin{array}{l}\text { Retrospective } \\
\text { cohort }\end{array}$ & 4 & $5^{\mathrm{b}}$ \\
\hline Marsh et al. [26] & 10 & 50 & $\mathrm{~T}$ & 100 & BT & $\begin{array}{r}\text { Retrospective } \\
\text { comparison }\end{array}$ & 3 & $9^{c}$ \\
\hline McNally et al. [27] & 18 & - & $\mathrm{T}$ & 100 & BT & Prospective cohort & 4 & $9^{c}$ \\
\hline McNally et al. [27] & 16 & - & $\mathrm{T}$ & 100 & BT & Prospective cohort & 4 & $9^{c}$ \\
\hline Megas et al. [28] & 9 & 78 & $\mathrm{~T}$ & 100 & BT & $\begin{array}{l}\text { Retrospective } \\
\text { cohort }\end{array}$ & 4 & $5^{\mathrm{b}}$ \\
\hline Sadek et al. [36] & 14 & 86 & $\mathrm{~T}$ & 100 & BT & $\begin{array}{r}\text { Retrospective } \\
\text { comparison }\end{array}$ & 3 & $12^{\mathrm{c}}$ \\
\hline Shyam et al. [38] & 5 & 100 & $\mathrm{~F}$ & 0 & BT & $\begin{array}{l}\text { Prospective com- } \\
\text { parison }\end{array}$ & 2 & $14^{\mathrm{c}}$ \\
\hline Tetsworth et al. [39] & 21 & 86 & $\mathrm{~T}$ & 100 & BT & $\begin{array}{r}\text { Retrospective } \\
\text { comparison }\end{array}$ & 3 & $14^{\mathrm{c}}$ \\
\hline $\mathrm{Xu}$ et al. [45] & 30 & 70 & $\mathrm{~T}$ & 100 & BT & $\begin{array}{l}\text { Retrospective } \\
\text { cohort }\end{array}$ & 4 & $6^{\mathrm{b}}$ \\
\hline Yin et al. [47] & 100 & 92 & $\mathrm{~T}, \mathrm{~F}$ & 65 & BT & $\begin{array}{l}\text { Retrospective } \\
\text { cohort }\end{array}$ & 4 & $6^{\mathrm{b}}$ \\
\hline Zhang et al. [50] & 24 & 71 & $\mathrm{~T}$ & 100 & BT & $\begin{array}{l}\text { Prospective com- } \\
\text { parison }\end{array}$ & 3 & $9^{\mathrm{b}}$ \\
\hline Chim et al. [13] & 28 & 75 & $\mathrm{~T}$ & 100 & BTAB & $\begin{array}{l}\text { Retrospective } \\
\text { cohort }\end{array}$ & 4 & $4^{\mathrm{b}}$ \\
\hline Eralp et al. [20] & 13 & 62 & $\mathrm{~T}, \mathrm{~F}$ & 54 & BTAB & $\begin{array}{l}\text { Retrospective } \\
\text { cohort }\end{array}$ & 4 & $5^{\mathrm{b}}$ \\
\hline Eralp et al. [17] & 29 & 69 & $\mathrm{~T}$ & 100 & BTAB & $\begin{array}{r}\text { Retrospective } \\
\text { comparison }\end{array}$ & 3 & $11^{\mathrm{c}}$ \\
\hline Napora et al. [31] & 75 & 76 & $\mathrm{~T}$ & 100 & BTAB & $\begin{array}{l}\text { Retrospective } \\
\text { cohort }\end{array}$ & 4 & $5^{\mathrm{b}}$ \\
\hline Tong et al. [40] & 19 & 79 & $\mathrm{~T}, \mathrm{~F}$ & 68 & BTAB & $\begin{array}{r}\text { Retrospective } \\
\text { comparison }\end{array}$ & 3 & $14^{\mathrm{c}}$ \\
\hline
\end{tabular}

$L o E$ level of evidence, $P c t$. percentage, $P t$ patients, $F R I$ fracture-related infection, $T$ tibia, $F$ femur, $A$ ankle, $f$ foot, $U$ ulna, $R$ radius, $H$ humerus, $C G$ cancellous graft, $C G A B$ cancellous graft with local antibiotics, $I M$ induced membrane technique, $V G$ vascularized graft, $B T$ bone transport, $B T A B$ bone transport with local antibiotics

${ }^{a}$ Methodological Index for Non-Randomized Studies (7)

${ }^{\mathrm{b}}$ Out of 16

${ }^{\mathrm{c}}$ Out of 24 


\section{Appendix 3: Funnel plots for each clinical outcome}

A: Primary healing

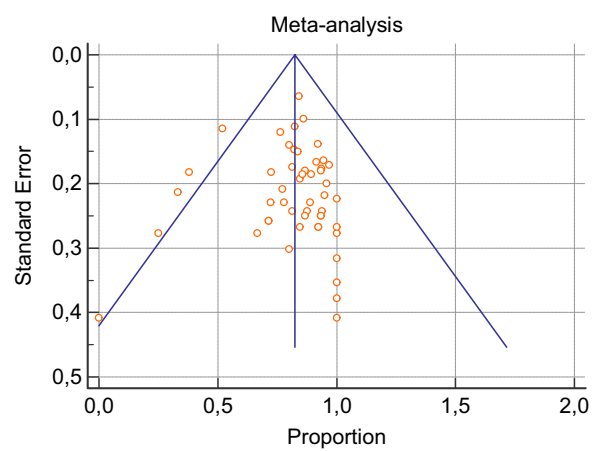

B: Total healing

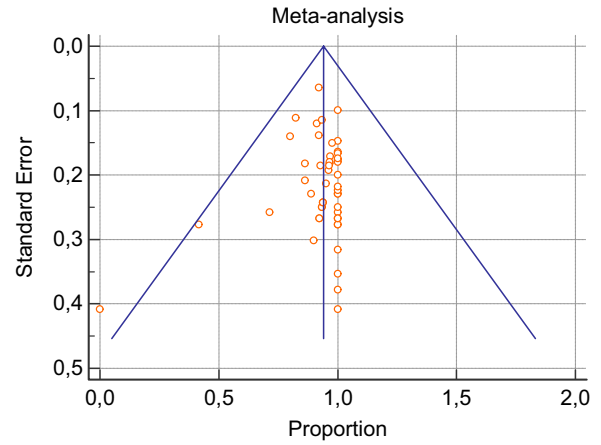

C: Recurrence of infection

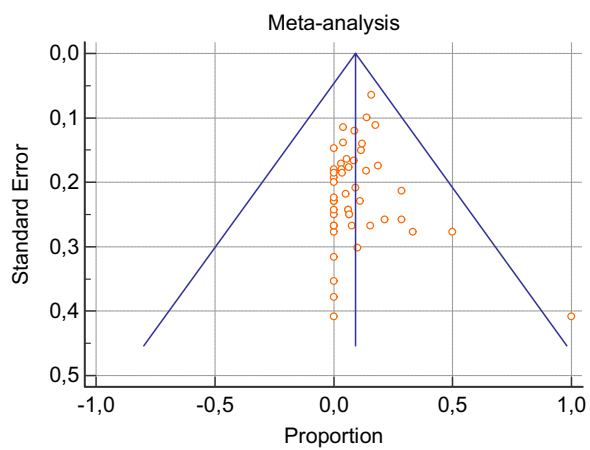

D: Amputation

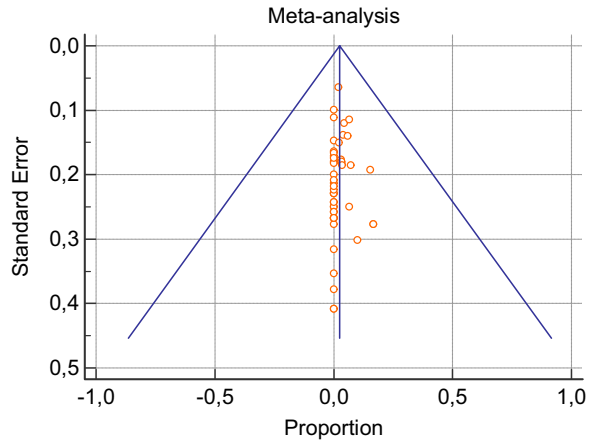




\section{Appendix 4: Forest plots for each clinical outcome, organized by treatment type}

A: Primary healing

Cancellous graft

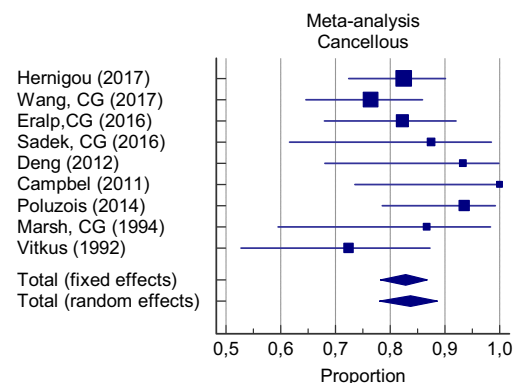

Cancellous graft with local antibiotics

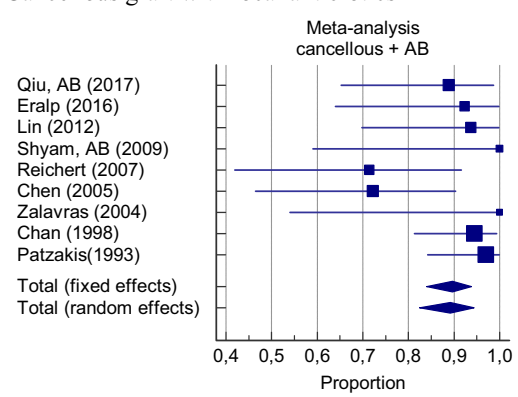

B: Total healing

Cancellous graft

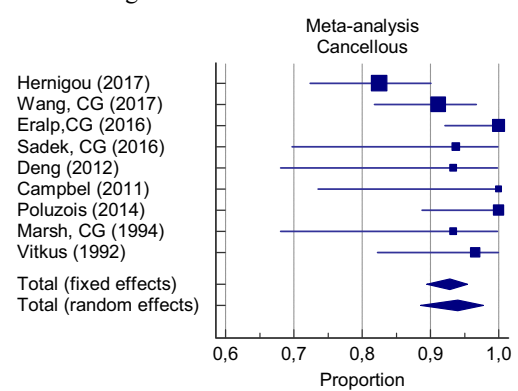

Cancellous graft with local antibiotics

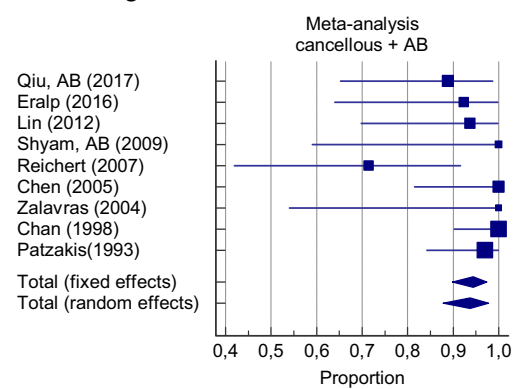

Induced membrane technique

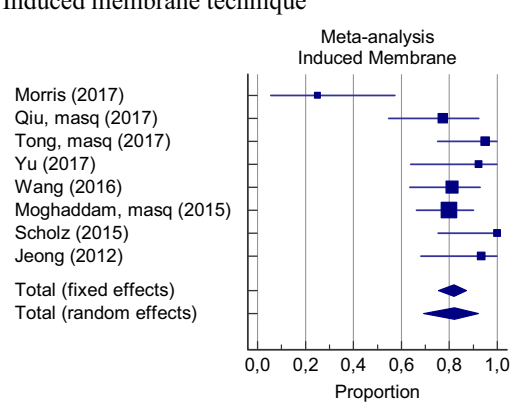

Vascularized grafts

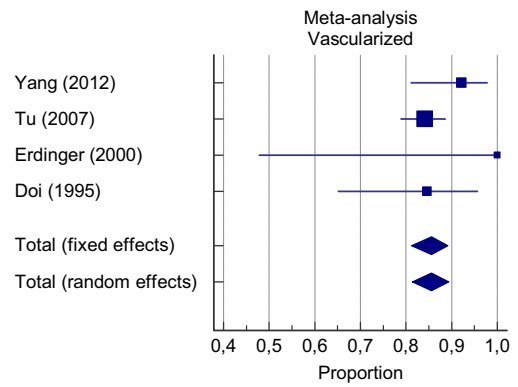

Induced membrane technique

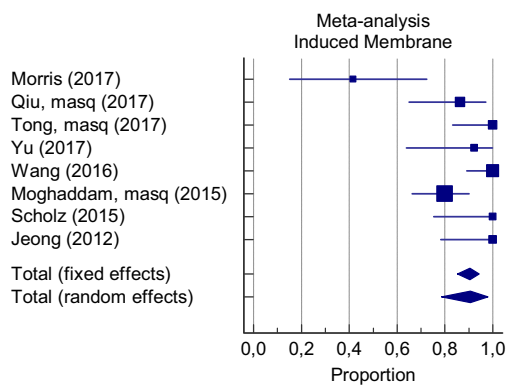

Vascularized grafts

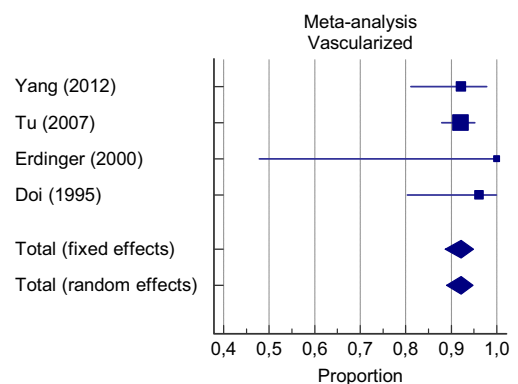

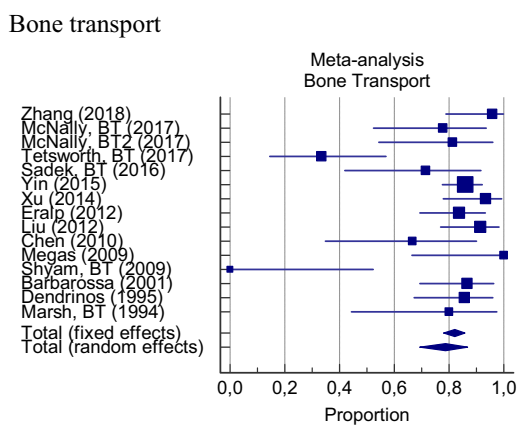

Bone transport with local antibiotics

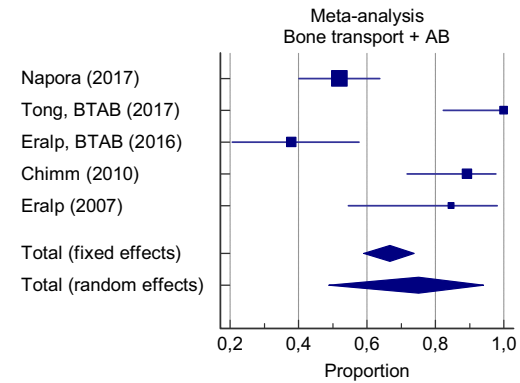

Bone transport

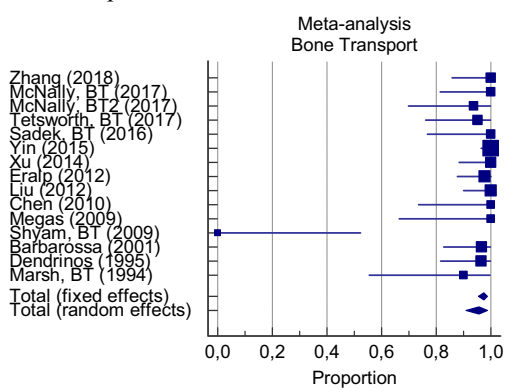

Bone transport with local antibiotics

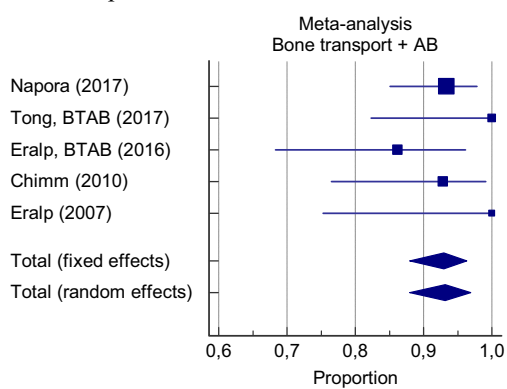




\section{C: Recurrence of infection}

Cancellous graft

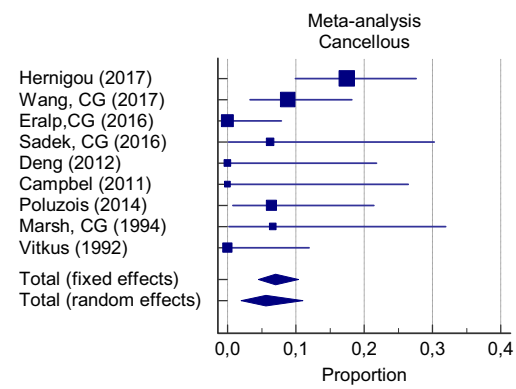

Cancellous graft with local antibiotics

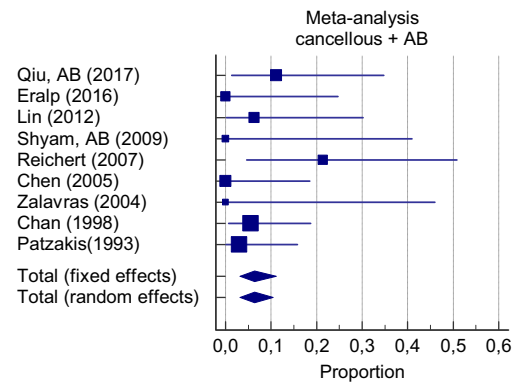

D: Amputation

Cancellous graft

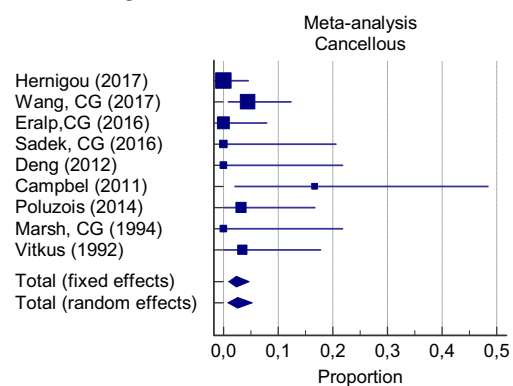

Cancellous graft with local antibiotics

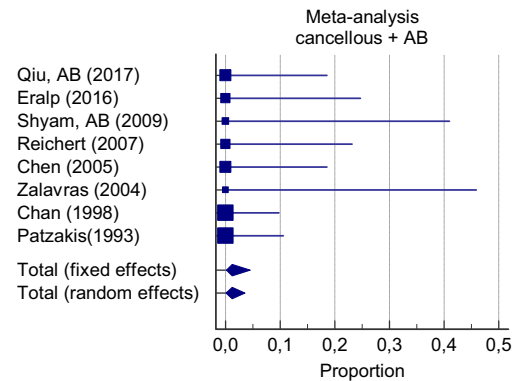

Induced membrane technique

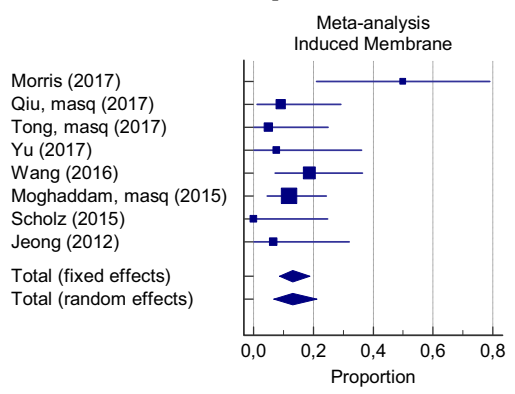

Vascularized grafts

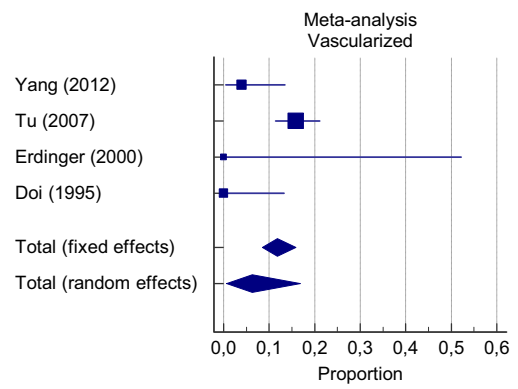

Induced membrane technique

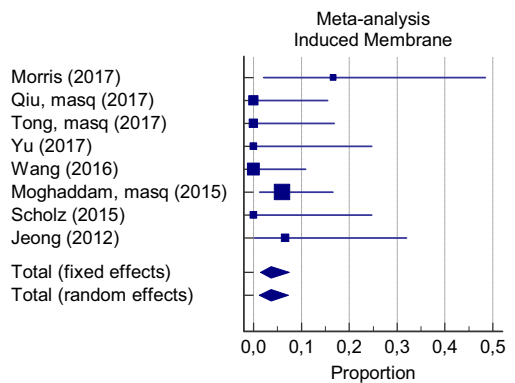

Vascularized grafts

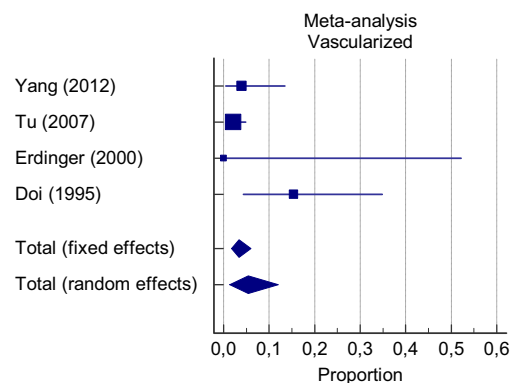

Bone transport

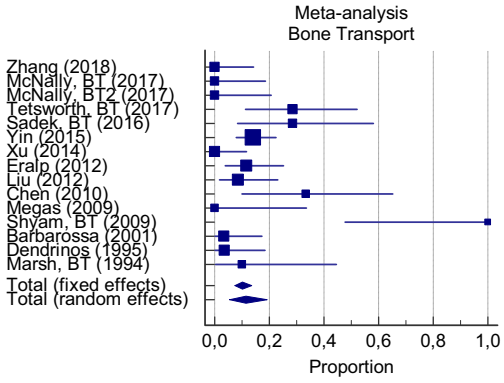

Bone transport with local antibiotics

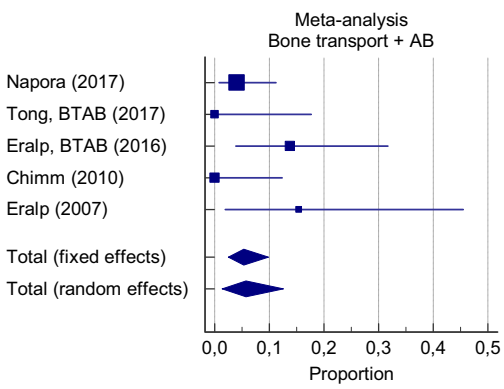

Bone transport

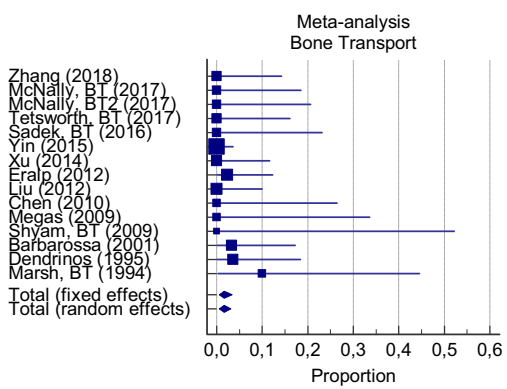

Bone transport with local antibiotics

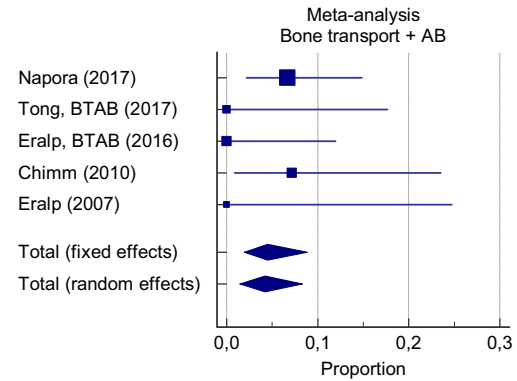




\section{References}

1. Court-Brown CM (2005) Fractures of the tibia and fibula. Lippincott Williams \& Wilkins, Philadelphia

2. Bhandari M, Guyatt G, Tornetta P 3rd, Schemitsch EH, Swiontkowski M, Sanders D, Walter SD (2008) Randomized trial of reamed and unreamed intramedullary nailing of tibial shaft fractures. J Bone Jt Surg Am 90:2567-2578

3. Sanders DW, Bhandari M, Guyatt G, Heels-Ansdell D, Schemitsch EH, Swiontkowski M, Tornetta P 3rd, Walter S, Investigators S (2014) Critical-sized defect in the tibia: is it critical? Results from the SPRINT trial. J Orthop Trauma 28:632-635

4. Lovati $\mathrm{AB}$, Romanò $\mathrm{CL}$, Bottagisio M, Monti L, De Vecchi E, Previdi S, Accetta R, Drago L (2016) Modeling staphylococcus epidermidis-induced non-unions: subclinical and clinical evidence in rats. PLoS ONE. https://doi.org/10.1371/journal.pone.0147447

5. Bilgili F, Balci HI, Karaytug K, Sariyilmaz K, Atalar AC, Bozdag E, Tuna M, Bilgic B, Gurler N (2015) Can normal fracture healing be achieved when the implant is retained on the basis of infection? An experimental animal model. Clin Orthop Relat Res 473:3190 3196. https://doi.org/10.1007/s11999-015-4331-9

6. Moher D, Liberati A, Tetzlaff J, Altman DG, Prisma Group (2009) Preferred reporting items for systematic reviews and meta-analyses: the PRISMA statement. Ann Intern Med 151:264-269

7. Slim K, Nini E, Forestier D, Kwiatkowski F, Panis Y, Chipponi J (2003) Methodological index for non-randomized studies (minors): development and validation of a new instrument. ANZ J Surg 73:712-716

8. Barbarossa V, Matković BR, Vučić N, Bielen M, Gluhinić M (2001) Treatment of osteomyelitis and infected non-union of the femur by a modified Ilizarov technique: follow-up study. Croat Med J 42:634-641

9. Campbell R, Berry MG, Deva A, Harris IA (2011) Aggressive management of tibial osteomyelitis shows good functional outcomes. Eplasty 11:e3

10. Chan YS, Ueng SWN, Wang CJ, Lee SS, Chao EK, Shin CH (1998) Management of small infected tibial defects with antibiotic-impregnated autogenic cancellous bone grafting. J Trauma Inj Infect Crit Care 45:758-764. https://doi.org/10.1097/00005 373-199810000-00023

11. Chen CE, Ko JY, Pan CC (2005) Results of vancomycin-impregnated cancellous bone grafting for infected tibial nonunion. Arch Orthop Trauma Surg 125:369-375. https://doi.org/10.1007/s0040 2-005-0794-6

12. Chen CM, Su AW, Chiu FY, Chen TH (2010) A surgical protocol of ankle arthrodesis with combined Ilizarov's distraction-compression osteogenesis and locked nailing for osteomyelitis around the ankle joint. J Trauma Inj Infect Crit Care 69:660-665. https:// doi.org/10.1097/TA.0b013e3181bc01e6

13. Chim H, Sontich JK, Kaufman BR (2011) Free tissue transfer with distraction osteogenesis is effective for limb salvage of the infected traumatized lower extremity. Plast Reconstr Surg 127:2364-2372

14. Dendrinos GK, Kontos S, Lyritsis E (1995) Use of the Ilizarov technique for treatment of non-union of the tibia associated with infection. J Bone Jt Surg 77:835-846

15. Deng Z, Cai L, Jin W, Ping A, Wei R (2014) One-stage reconstruction with open bone grafting and vacuum-assisted closure for infected tibial non-union. Arch Med Sci 10:764-772. https://doi. org/10.5114/aoms.2013.34411

16. Doi K, Kawakami F, Hiura Y, Oda T, Sakai K, Kawai S (1995) One-stage treatment of infected bone defects of the tibia with skin loss by free vascularized osteocutaneous grafts. Microsurgery $16: 704-712$
17. Eralp İL, Kocaoğlu M, Dikmen G, Azam ME, Balcı Hİ, Bilen FE (2016) Treatment of infected nonunion of the juxta-articular region of the distal tibia. Acta Orthopaedica et Traumatologica Turcica 50:139-146. https://doi.org/10.3944/aott.2015.15.0147

18. Eralp L, Balci HI, Kocaoglu M, Sen C, Celiktas M, Tomak Y, Gulsen M, Dikmen G (2016) Is acute compression and distraction superior to segmental bone transport techniques in chronic tibial osteomyelitis? Comparison of distraction osteogenesis techniques. Acta Orthop Belg 82:599-609

19. Eralp L, Kocaoğlu M, Polat G, Baş A, Dirican A, Azam ME (2012) A comparison of external fixation alone or combined with intramedullary nailing in the treatment of segmental tibial defects. Acta Orthop Belg 78:652-659

20. Eralp L, Kocaoglu M, Rashid H (2007) Reconstruction of segmental bone defects due to chronic osteomyelitis with use of an external fixator and an intramedullary nail: surgical technique. J Bone Jt Surg 89:183-195. https://doi.org/10.2106/jbjs.g.00306

21. Erdinger K, Windhofer C, Papp C (2001) Osteomuscular latissimus dorsi scapula flap to repair chronic, posttraumatic osteomyelitis of the lower leg. Plast Reconstr Surg 107:1430-1435

22. Hernigou P, Dubory A, Homma Y, Flouzat Lachaniette $\mathrm{CH}$, Chevallier N, Rouard H (2017) Single-stage treatment of infected tibial non-unions and osteomyelitis with bone marrow granulocytes precursors protecting bone graft. Int Orthop. https://doi. org/10.1007/s00264-017-3687-8

23. Jeong JJ, Lee HS, Choi YR, Kim SW, Seo JH (2012) Surgical treatment of non-diabetic chronic osteomyelitis involving the foot and ankle. Foot Ankle Int 33:128-132. https://doi.org/10.3113/ fai. 2012.0128

24. Lin CC, Chen CM, Chiu FY, Su YP, Liu CL, Chen TH (2012) Staged protocol for the treatment of chronic tibial shaft osteomyelitis with Ilizarov's technique followed by the application of intramedullary locked nail. Orthopedics 35:e1769-e1774

25. Liu T, Yu XD, Zhang XS, Li ZH, Zeng W (2012) One-stage management of post-traumatic tibial infected nonunion using bone transport after debridement. Turk J Med Sci 42:1111-1120

26. Marsh JL, Prokuski L, Biermann JS (1994) Chronic infected tibial nonunions with bone loss: conventional techniques versus bone transport. Clin Orthop Relat Res ${ }^{\circledR}$ 301:139-146

27. McNally M, Ferguson J, Kugan R, Stubbs D (2017) Ilizarov treatment protocols in the management of infected nonunion of the tibia. J Orthop Trauma 31:S47-S54

28. Megas P, Saridis A, Kouzelis A, Kallivokas A, Mylonas S, Tyllianakis M (2010) The treatment of infected nonunion of the tibia following intramedullary nailing by the Ilizarov method. Injury 41:294-299

29. Moghaddam A, Zietzschmann S, Bruckner T, Schmidmaier G (2015) Treatment of atrophic tibia non-unions according to 'diamond concept': results of one- and two-step treatment. Injury 46:S39-S50. https://doi.org/10.1016/s0020-1383(15)30017-6

30. Morris R, Hossain M, Evans A, Pallister I (2017) Induced membrane technique for treating tibial defects gives mixed results. Bone Jt J 99-B:680-685

31. Napora JK, Weinberg DS, Eagle BA, Kaufman BR, Sontich JK (2017) Hexapod frame stacked transport for tibial infected nonunions with bone loss: analysis of use of adjunctive stability. J Orthop Trauma 31:393-399

32. Patzakis MJ, Mazur K, Wilkins J, Sherman R, Holtom P (1993) Septopal beads and autogenous bone grafting for bone defects in patients with chronic osteomyelitis. Clin Orthop Relat Res ${ }^{\circledR}$ 295:112-118

33. Polyzois VD, Galanakos SP, Tsiampa VA, Papakostas ID, Kouris NK, Avram AM, Papalois AE, Ignatiadis IA (2011) The use of Papineau technique for the treatment of diabetic and non-diabetic lower extremity pseudoarthrosis and chronic osteomyelitis. Diabet Foot Ankle 2:1-7. https://doi.org/10.3402/dfa.v2i0.5920 
34. Qiu XS, Chen YX, Qi XY, Shi HF, Wang JF, Xiong J (2017) Outcomes of cement beads and cement spacers in the treatment of bone defects associated with post-traumatic osteomyelitis. BMC Musculoskelet Disord 18:256. https://doi.org/10.1186/s1289 1-017-1614-1

35. Reichert P, Rutowski R, Gosk J, Zimmer K, Wiacek R (2007) Treatment of infected nonunion of long bones. Adv Clin Exp Med 16:403-409

36. Sadek AF, Laklok MA, Fouly EH, Elshafie M (2016) Two stage reconstruction versus bone transport in management of resistant infected tibial diaphyseal nonunion with a gap. Arch Orthop Trauma Surg 136:1233-1241

37. Scholz AO, Gehrmann S, Glombitza M, Kaufmann RA, Bostelmann R, Flohe S, Windolf J (2015) Reconstruction of septic diaphyseal bone defects with the induced membrane technique. Injury 46(Suppl 4):S121-S124

38. Shyam AK, Sancheti PK, Patel SK, Rocha S, Pradhan C, Patil A (2009) Use of antibiotic cement-impregnated intramedullary nail in treatment of infected non-union of long bones. Indian J Orthop 43:396-402

39. Tetsworth K, Paley D, Sen C, Jaffe M, Maar DC, Glatt V, Hohmann E, Herzenberg JE (2017) Bone transport versus acute shortening for the management of infected tibial non-unions with bone defects. Injury 48:2276-2284

40. Tong K, Zhong Z, Peng Y, Lin C, Cao S, Yang Y, Wang G (2017) Masquelet technique versus Ilizarov bone transport for reconstruction of lower extremity bone defects following posttraumatic osteomyelitis. Injury 48:1616-1622. https://doi.org/10.1016/j. injury.2017.03.042

41. Tu YK, Yen CY (2007) Role of vascularized bone grafts in lower extremity osteomyelitis. Orthop Clin N Am 38:37-49. https://doi. org/10.1016/j.ocl.2006.10.005

42. Vitkus K, Vitkus M, Cierny Iii G, Nahai F (1992) Reconstruction of large infected tibia defects. Ann Plast Surg 29:97-108

43. Wang X, Luo F, Huang K, Xie Z (2016) Induced membrane technique for the treatment of bone defects due to post-traumatic osteomyelitis. Bone Joint Res 5(3):101-105. https://doi. org/10.1302/2046-3758.53.2000487

44. Wang Y, Jiang H, Deng Z, Jin J, Meng J, Wang J, Zhao J, Sun G, Qian H (2017) Comparison of monolateral external fixation and internal fixation for skeletal stabilisation in the management of small tibial bone defects following successful treatment of chronic osteomyelitis. Biomed Res Int. https://doi. org/10.1155/2017/6250635

45. Xu K, Fu X, Li YM, Wang CG, Li ZJ (2014) A treatment for large defects of the tibia caused by infected nonunion: Ilizarov method with bone segment extension. Ir J Med Sci 183:423-428

46. Yang YF, Xu ZH, Zhang GM, Wang JW, Hu SW, Hou ZQ, Xu DC (2013) Modified classification and single-stage microsurgical repair of posttraumatic infected massive bone defects in lower extremities. J Reconstr Microsurg 29:593-600. https://doi. org/10.1055/s-0033-1348064

47. Yin P, Zhang LH, Li TT, Zhang LC, Wang GQ, Li JT, Liu JH, Zhou JF, Zhang Q, Tang PF (2015) Infected nonunion of tibia and femur treated by bone transport. J Orthop Surg Res 10:49

48. Yu X, Wu H, Li J, Xie Z (2017) Antibiotic cement-coated locking plate as a temporary internal fixator for femoral osteomyelitis defects. Int Orthop 41:1851-1857. https://doi.org/10.1007/s0026 4-016-3258-4

49. Zalavras CG, Patzakis MJ, Thordarson DB, Shah S, Sherman R, Holtom P (2004) Infected fractures of the distal tibial metaphysis and plafond-achievement of limb salvage with free muscle flaps, bone grafting, and ankle fusion. Clin Orthop Relat Res® 427:57-62

50. Zhang H, Xue F, Jun Xiao H (2018) Ilizarov method in combination with autologous mesenchymal stem cells from iliac crest shows improved outcome in tibial non-union. Saudi J Biol Sci 25:819-825

51. Tiemann AH, Schmidt HG, Braunschweig R, Hofmann GO (2009) Strategies for the analysis of osteitic bone defects at the diaphysis of long bones. Strateg Trauma Limb Reconstr 4:13-18

52. Metsemakers WJ, Kuehl R, Moriarty TF, Richards RG, Verhofstad MHJ, Borens O, Kates S, Morgenstern M (2018) Infection after fracture fixation: current surgical and microbiological concepts. Injury 49:511-522

53. Lasanianos NG, Kanakaris NK, Giannoudis PV (2010) Current management of long bone large segmental defects. Orthop Trauma 24:149-163. https://doi.org/10.1016/j.mporth.2009.10.003

54. Kadhim M, Holmes L, Gesheff MG, Conway JD (2017) Treatment options for nonunion with segmental bone defects: systematic review and quantitative evidence synthesis. J Orthop Trauma 31:111-119. https://doi.org/10.1097/BOT.0000000000000700

55. Mauffrey C, Hak DJ (2017) Tibial defect reconstruction: a plea for standardization. J Orthop Trauma 31(Suppl 5):S1-S2

56. Metsemakers WJ, Claes G, Terryn PJ, Belmans A, Hoekstra H, Nijs S (2017) Reamer-Irrigator-Aspirator bone graft harvesting for treatment of segmental bone loss: analysis of defect volume as independent risk factor for failure. Eur J Trauma Emerg Surg. https://doi.org/10.1007/s00068-017-0821-7

57. Marais LC, Ferreira N, Aldous C, le Roux TLB (2014) The management of chronic osteomyelitis: part I-diagnostic work-up and surgical principles. S Afr Orthop J 13:42-48

58. Bose D, Kugan R, Stubbs D, McNally M (2015) Management of infected nonunion of the long bones by a multidisciplinary team. Bone Jt J 97B:814-817

59. McNally MA (2016) Decision-making in infected nonunion: is the surgery more important than the condition? Bone $\mathrm{Jt} \mathbf{J}$ 98-B:435-436

60. Hotchen AJ, McNally MA, Sendi P (2017) The classification of long bone osteomyelitis: a systemic review of the literature. J Bone Jt Infect 2:167-174

61. Romano CL, Romano D, Logoluso N, Drago L (2011) Bone and joint infections in adults: a comprehensive classification proposal. Eur Orthop Traumatol 1:207-217

62. Nauth A, Schemitsch E, Norris B, Nollin Z, Watson JT (2018) Critical-size bone defects: is there a consensus for diagnosis and treatment? J Orthop Trauma 32:S7-S11

63. May JW Jr, Jupiter JB, Weiland AJ, Byrd HS (1989) Clinical classification of post-traumatic tibial osteomyelitis. J Bone Jt Surg $71: 1422-1428$

64. Stafford PR, Norris BL (2010) Reamer-irrigator-aspirator bone graft and bi Masquelet technique for segmental bone defect nonunions: a review of 25 cases. Injury 41(Suppl 2):S72-S77

65. Makridis KG, Tosounidis T, Giannoudis PV (2013) Management of infection after intramedullary nailing of long bone fractures: treatment protocols and outcomes. Open Orthop J 7:219-226

66. Giannoudis PV (2016) Treatment of bone defects: bone transport or the induced membrane technique? Injury 47:291-292

Publisher's Note Springer Nature remains neutral with regard to jurisdictional claims in published maps and institutional affiliations. 